\title{
Neutron Characterization of BNCT Water Phantom Based on Kartini Research Reactor Using PHITS
}

\author{
Vika Hutaria ${ }^{1}$, Susilo $^{2}$, Yohannes Sardjono \\ IDepartment of Physics, Faculty of Mathematics and Siences, State University of Semarang, Semarang 50229, Indonesia \\ ${ }^{2}$ Pusat Sains dan Teknologi Akselerator - Badan Tenaga Nuklir Nasional (PSTA-BATAN), Yogyakarta 55281, Indonesia
}

\section{ARTICLE INFO}

Article history:

Received: 20 August 2018

Received in revised form: 20 October 2018

Accepted: 15 January 2019

Keywords:

Keyword BNCT

Keyword Water phantom

Keyword Neutron

Keyword Reactor

\begin{abstract}
A B S T R A C T
Boron Neutron Capture Therapy (BNCT) is a therapy that utilizes the interaction of thermal neutrons with a boron-10 core that produces alpha particles and lithium nuclei. The result of this boron reaction has high linear energy transfer (LET). BNCT has an advantage over other radiation therapy in that it has a high selectivity level. This research was run using PHITS simulation to find out the value of neutron flux spread over a water phantom. The conclusion of the research is the distribution of neutron flux in the water phantom without boron is higher the the distribution of neutron flux in the water phantom containing boron.
\end{abstract}

\section{INTRODUCTION}

Cancer is one of the leading causes of death worldwide. Cancer is the second leading cause of death globally. Lung, prostate, colorectal, gastric and liver cancers are the most common type of cancer in men, while breast, colorectal, lung, cervix and stomach cancers are most common among women [1][5]. Cancer is a group of diseases characterized by uncontrolled growth and the spread of abnormal cells. Cancer is a general term for one large group of diseases that can affect any part of the body [2].

Cancer is caused by two factors: internal and external factors. Internal factors are caused by mutations genetic, hormones, and immune conditions. External factors are caused by tobacco, infectious organisms, radiation \& UV rays and unhealthy diets[3]. In Indonesia, the World Health Organization (WHO) predicted that by 2030 the number of cancer patients will be very high; and even now the quality and quantity of the treatment is not sufficient[4].

\footnotetext{
*E-mail: vikahutaria17@gmail.com
}

According to sources, between $30 \%$ and $50 \%$ of cancer deaths can be prevented by modifying or avoiding major risk factors, including smoking and alcohol consumption[6]. Along with many deaths being caused by cancer in the world, the treatments being used are developing.

Some types of cancer treatment that already exist are Chemotherapy, Radiotherapy, Surgery, and Brachytherapy [4][15][16][17]. Chemotherapy uses drugs to weaken cancer cells but also has the side effect of damaging the immune system. Radiotherapy uses highdose of radiation sourced from radioactive energy in addition, the radiotherapy beam is less effective because it has a low linear energy transfer (LET). Surgery is usually used for initial treatment when the condition of the tumor is still in its early stages [7]. Such cancer treatment can cause side effects that occur when treatment affects tissues or healthy organs[1][18][19][20]. .To overcome these weaknesses BNCT has been developed with selective characteristic to cancer cells.

BNCT is a method of radiation therapy that is based on the ability of nonradioactive Boron-10 to capture neutrons with low energy 
(thermal neutrons)[8]. This interaction produces $11 \mathrm{~B}$ by emitting $\alpha$ and lithium nuclei. The result of this boron reaction has high LET (Sauerwein et al, 2012). The recommended epithermal neutron flux for therapy is $10^{9} \mathrm{n} / \mathrm{cm} 2 \mathrm{~s}$, which has the most profound effectiveness in tumors [9]. BNCT has been clinically used to treat various cancers around the world [10][14].

Thermal and epithermal neutrons play an important role in the efficiency of BNCT treatment. Thermal neutrons can easily reach cancer located near the surface tissue (skin) with energy less than $0.5 \mathrm{eV}$, whereas for epithermal neutrons it is targeted to treat tumors with a deeper range with energy from $0.5 \mathrm{eV}$ to $10 \mathrm{keV}[11[12]$. Neutron flux is a measure of the intensity of neutron radiation.

The aims of this research are to find out the value of thermal and epithermal nuetron flux scattered in a water phantom by using the simulation program PHITS (Particle Heavy Ions Transport Simulation).

\section{MATERIALS AND METHODS}

\subsection{Research Instruments}

The research was conducted in Engineering Room of PSTA-BATAN YOGYAKARTA for 30 days. On February 6, 2017 to March 6, 2017. The research was conducted by running PHITS program, Input PHITS program (surface card, cell card, and data card) and was started by making the geometry of the water phantom with the dimensions of $20 \mathrm{~cm} \times 20 \mathrm{~cm} \times 20 \mathrm{~cm}$ and the geometry of the Kartini Research Reactor using the reactor neutron source according to the proprietary design of Rosilatul Zailani. Then the neutron flux was calculated by running the PHITS program with the neutron source from the Kartini Research Reactor (KRR). Characteristically the type of pool with power working at $250 \mathrm{KW}$ is used. The average thermal flux generated is about $1.2 \times 10^{13}$ $\mathrm{n} / \mathrm{cm}^{2} \mathrm{~s}$ and the average fast Flux is $2.5 \times 10^{12}$ $\mathrm{n} / \mathrm{cm}^{2} \mathrm{~s}[13]$. The Water phantom used contained $\mathrm{D}_{2} \mathrm{O}$ (Deutirium Oxide), was $30 \mathrm{~cm} \mathrm{x} 30 \mathrm{~cm} \mathrm{x}$ $30 \mathrm{~cm}$, and was wrapped in acrylic glass $1 \mathrm{~cm}$ thick. This research used two variants, that is, water phantoms without boron and water phantoms containing boron.

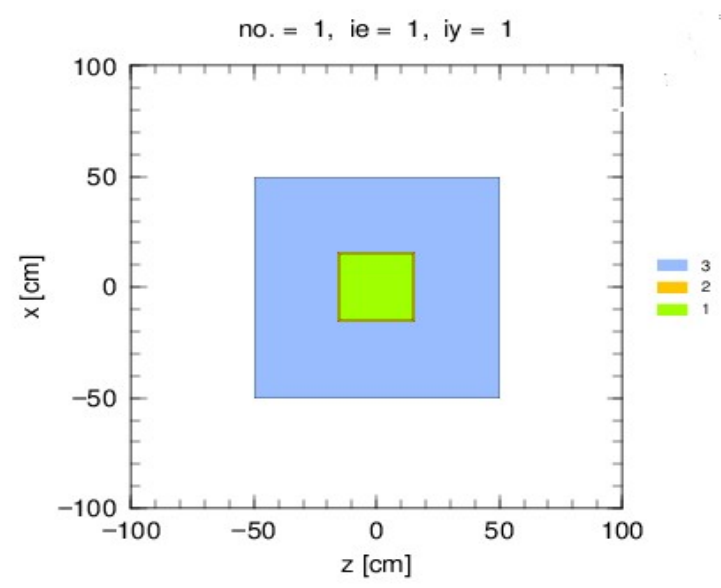

Fig 1. Geometry of water phantom without boron

In figure 1 the geometry of simulation where part 1 is a water phantom with the density 0.017 , part 2 is acrylic glass with 1.18 density, while part 3 is air with density 0.0012 .

\subsection{Shoot the Neutron Spectrum}

The neutron spectrum is shot into the phantom water from the left and interacts with the boron inside the water phantom. Then we can get the value of flux which is observed according to depth. The depth of the water phantom is divided in 6 part. Next, the spread of absorbent neutron flux was calculated using the PHITS program.

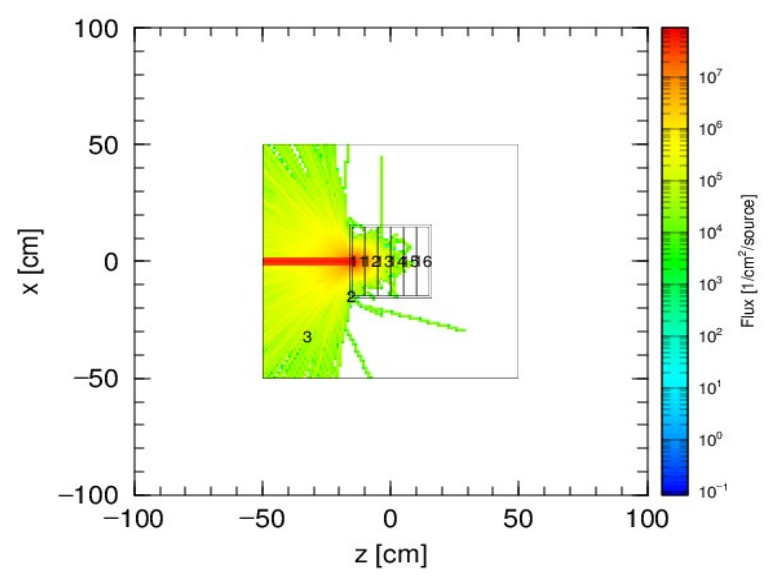

Figure 2. Shooting neutron spectrum at water phantom containing boron 


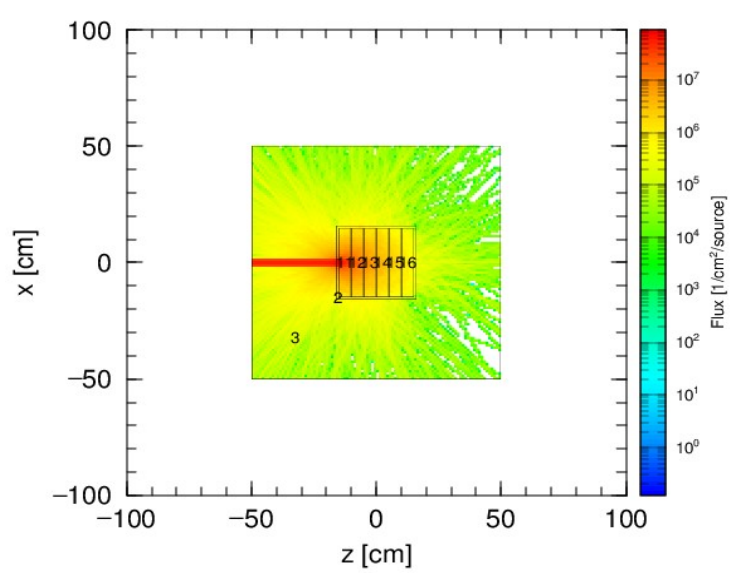

Figure 3. Shooting neutron spectrum at water phantom without boron

\subsection{Calculation of Dose}

To calculate neutron flux in water phantom one of the tally functions in the PHITS software was used, [T-deposit].

\section{RESULTS AND DISCUSSION}

\subsection{Water Phantom Containing Boron}

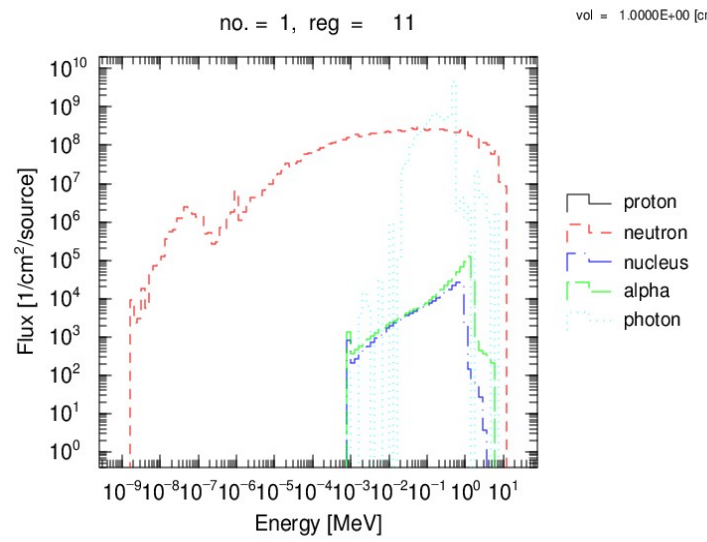

Figure 4. Neutron distribution on part 1

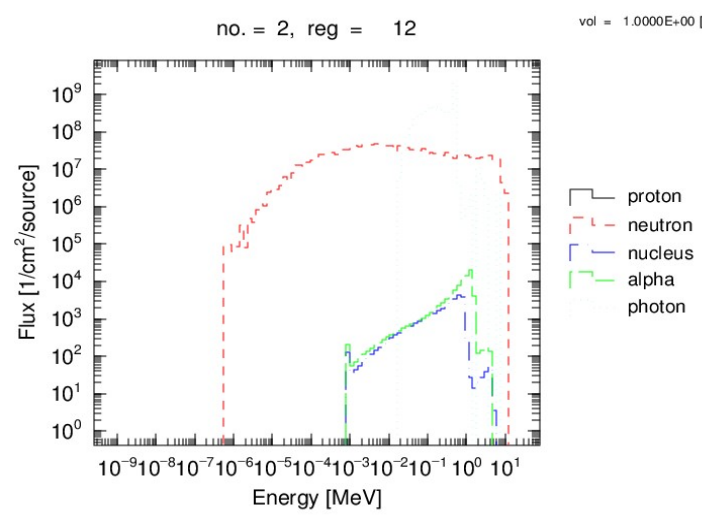

Figure 5. Neutron distribution on part 2

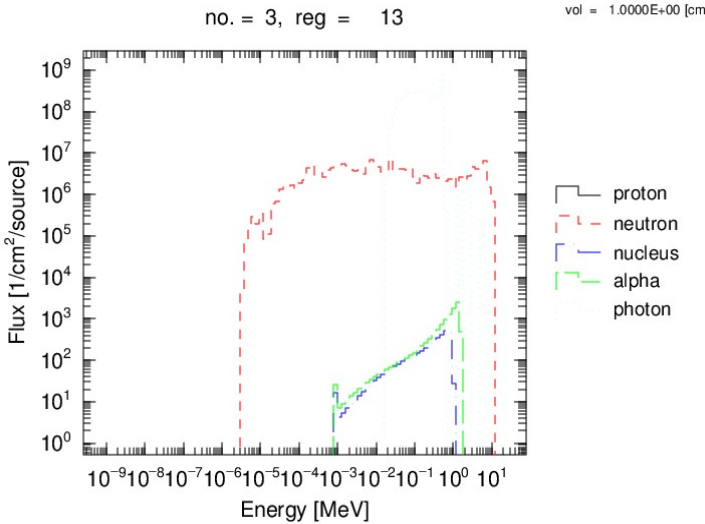

Figure 6. Neutron distribution on part 3

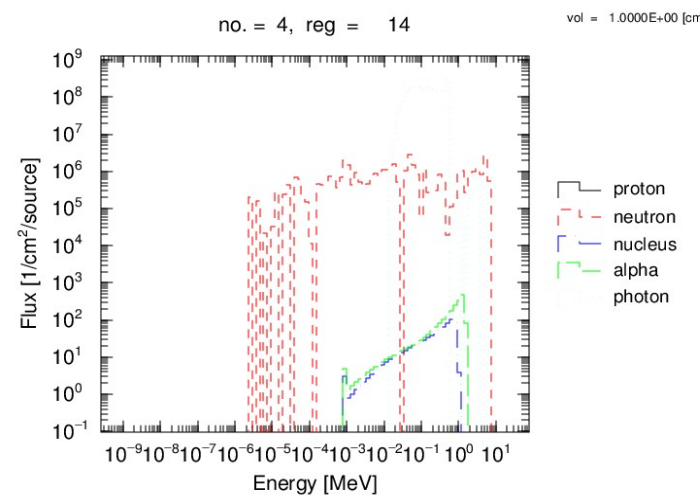

Figure 7. Neutron distribution on part 4

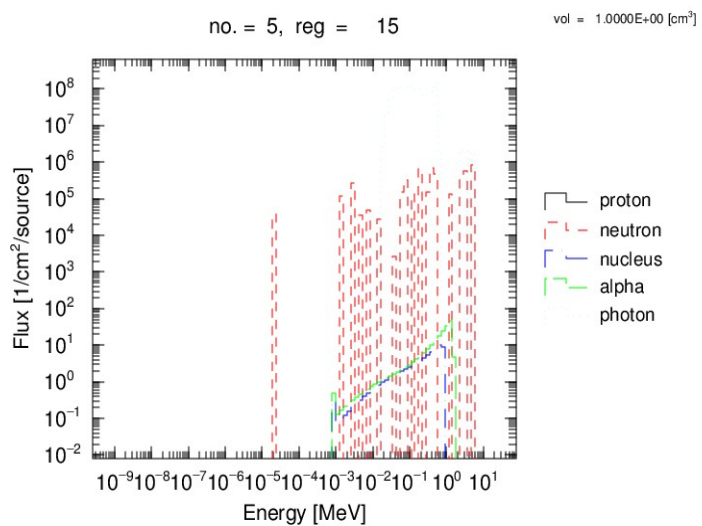

Figure 8. Neutron distribution on part 5

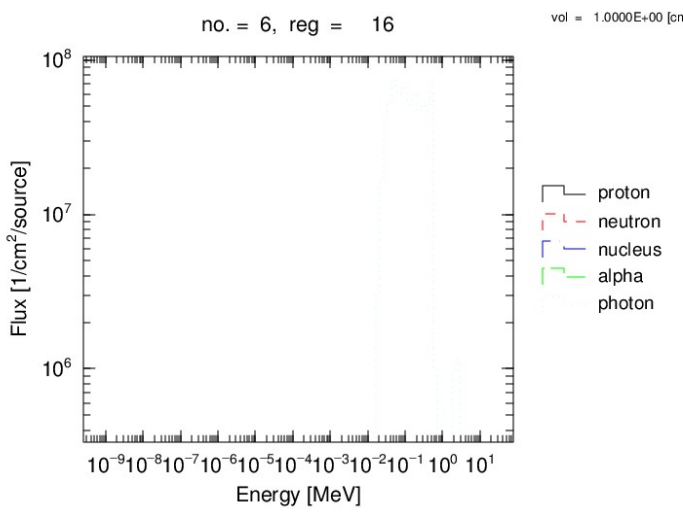

Figure 9. Neutron distribution on part 6 
Table 1. Neutron flux Water Phantom

\begin{tabular}{cc}
\hline Region & $1 / \mathrm{cm}^{\wedge} 2 /$ source \\
\hline 1 & $9.4300 \mathrm{E}+09$ \\
2 & $1.5530 \mathrm{E}+09$ \\
3 & $1.9234 \mathrm{E}+08$ \\
4 & $4.0219 \mathrm{E}+07$ \\
5 & $5.0744 \mathrm{E}+06$ \\
6 & $0.0000 \mathrm{E}+00$
\end{tabular}

Based on the Figure, the distribution of neutron flux on water phantom containing boron is not so low in the first region but in the last region there is no neutron flux distribution. It is caused by interaction between the neutrons and boron.

\subsection{Water Phantom Without Boron}

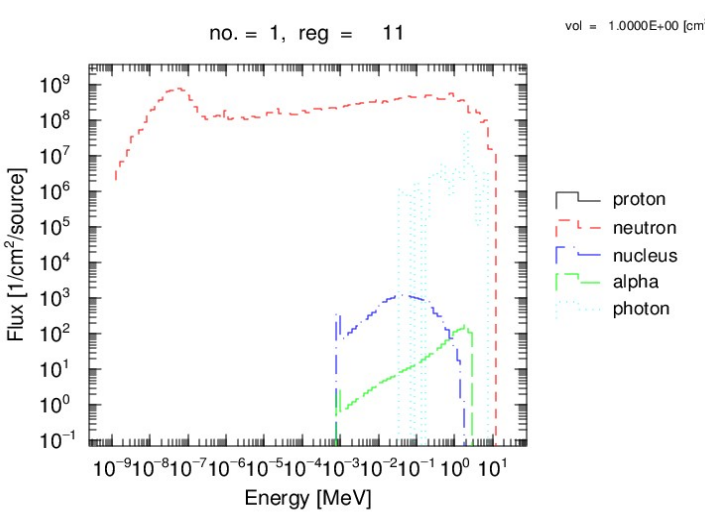

Figure 10. Neutron distribution on part 1

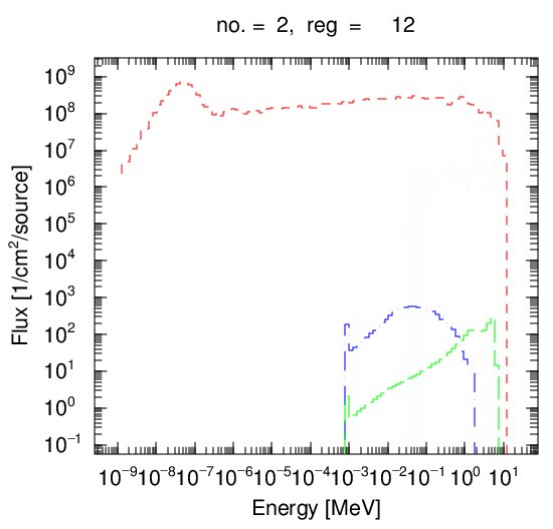

$\mathrm{vol}=1.0000 \mathrm{E}+00\left[\mathrm{~cm}^{3}\right.$

Figure 11. Neutron distribution on part 2

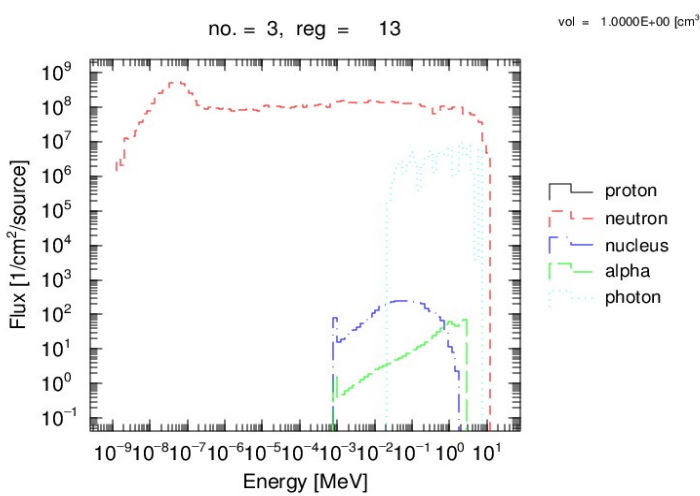

Figure 12. Neutron distribution on part 3

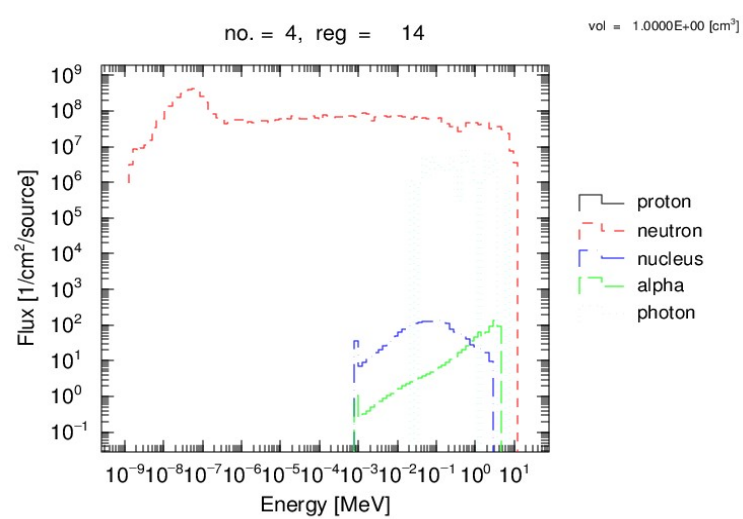

Figure 13. Neutron distribution on part 4

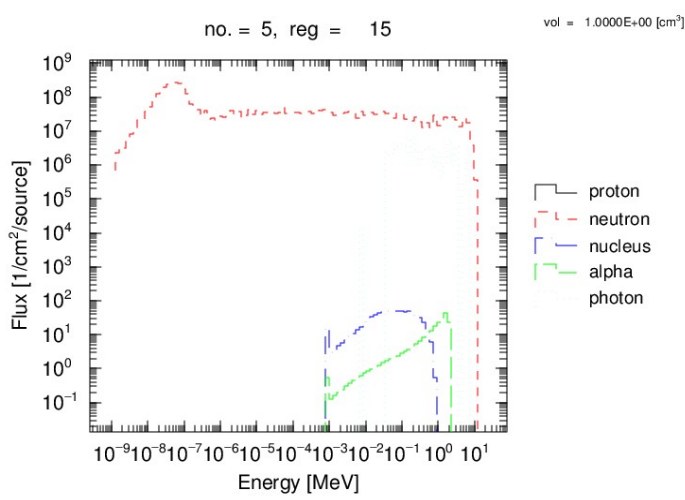

Figure 14. Neutron distribution on part 5

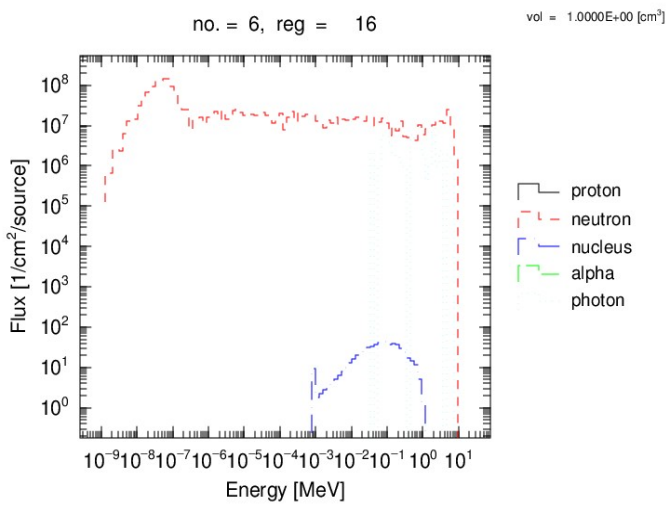


Figure 15. Neutron distribution on part 6

Table 2. Neutron flux Water Phantom

\begin{tabular}{cc}
\hline Region & $1 / \mathrm{cm}^{\wedge} 2 /$ source \\
\hline 1 & $2.6339 \mathrm{E}+10$ \\
2 & $1.9273 \mathrm{E}+10$ \\
3 & $1.2506 \mathrm{E}+10$ \\
4 & $7.6660 \mathrm{E}+09$ \\
5 & $4.4091 \mathrm{E}+09$ \\
6 & $2.2129 \mathrm{E}+09$ \\
\hline
\end{tabular}

In the neutron distribution on water phantom without boron, it is stable and high in the first and the last region because there is no interaction between neutrons and boron.

\section{CONCLUSION AND REMARKS}

The conclusion of the research is the distribution of neutron flux in the water phantom without boron is higher the the distribution of neutron flux in the water phantom containing boron.

\section{ACKNOWLEDGMENT}

The authors would like to thank the Accelerated Center for Nuclear Science and Technology, BATAN Yogyakarta for their help in the research.

\section{REFERENCES}

1. National Cancer Institute : 2016

2. American Cancer Society. Cancer Facts \& Figures 2016. Atlanta: American Cancer Society,Inc

3. Gónzalez-Soto K, Amgarou K, Lagares J I, Expósito M R, Gómez F, Domingo C, SánchezNieto B, Sánchez-Doblado F. 2013. Neutron distribution in radiotherapy treatment rooms. Dpto. Fisiología Médica y Biofísic

4. World Health Organization (2016)

5. IAEA (2014. PACT: Together Against Cancer. PACT Program Office. International Atomic Energy Agency. Venna: International Center.

6. Monshizadeh M, Kasesaz Y, Khalafi H, Hamidi S. 2015. MCNP design of thermal and epithermal neutron beam for BNCT at the Isfahan MNSR. Progress in Nuclear Energy 83:427-432

7. Wusko ikna urwatul. 2016. Optimasi kolimator dan dosimetri uji invivo boron neutron capture terapi (BNCT) pada beam port tembus reaktor kartini dengan metode simulasi monte carlo N-particle Extended (MCNPX) Tesis : UGM

8. Miyatake. et al. (2014). Boron Neutron Capture Therapy with Bevacizumab may Prolong the Survival of Recurrent Malignant Glioma Patients: four cases. Radiation Oncology. HIm 1-6

9. Zafer, Akan et al (2015). Boron Neutron Capture Therapy for Breast Cancer. International Journal of Women's Health and Reproduction Sciences Vol. 3, No. 2

10. Faghihi F, Khalili S. 2013. Beam shaping assembly of a D-T neutron source for BNCT and its dosimetry simulation in deeply-seated tumors. Radiation Physics and Chemistry 89:1-13.

11. J.G. Fantidis et. al., Optimised BNCT facility based on a compact D-D neutron generator. Int. J. Radiat. Res., October 2013; 11(4): 207-214. (2013)

12. J.G. Fantidis et. al., Optimised BNCT facility based on a compact D-D neutron generator. Int. J. Radiat. Res., October 2013; 11(4): 207-214. (2013)

13. Batan .go.id

14. Wolfgang A.G. Sauerwein . 2012. Neutron Capture Therapy: Principles and Application. Springer-Verlag Berlin Heidelberg 2012

15. News Medical Life Science. 2017. Brachytherapy Side Effect.

16. Cancer Research UK. Treatment.

17. Department Of Health And Human Services. 2012. What To Know About Brachytherapy (A Type of Internal Radiation Therapy). US : National Institutes of Health

18. Zafer, Akan et al (2015). Boron Neutron Capture Therapy for Breast Cancer. International Journal of Women's Health and Reproduction Sciences Vol. 3, No. 2

19. S. Triviño et al (2016). Neutron Dose Estimation in a Zero Power Nuclear Reactor. Radiation Physics and Chemistry 127 (2016) 62-67. Laboratorio de Investigación e Instrumentación en Física Aplicada a la Medicina e Imágenes por Rayos X (LIIFAMIRx), Universidad 


\section{Indonesian Journal of Physics and Nuclear Applications Volume 4, Number 1, February 2019, p. 16-21 e-ISSN 2550-0570, C FSM UKSW Publication}

Nacional de Córdoba, Av. M. Allende s/n, Córdoba, Argentina

20. National Cancer Institute (2015). Cancer Treatment. National Institutes of Health Zaidi, Lilia, et al. Monte Carlo based Dosimetry for NCT of Brain Tumor. 1Faculte de physique USTHB, Laboratoire SNIRM, BP 32 EL-Alia. EPJ Web of Conferences 128, 04003:2016h 